\title{
Renal nutcracker syndrome
}

\author{
Roberto Copetti ${ }^{1}$, Elisa Copetti ${ }^{2}$
}

${ }^{1}$ Emergency Department, Latisana General Hospital, Latisana (Udine), Italy, ${ }^{2}$ Department of Anesthesia and Intensive Care, Udine, Italy

A previously healthy, 31 year old woman was admitted to the emergency room with left flank pain and macrohaematuria, which began after jogging. The physical examina-

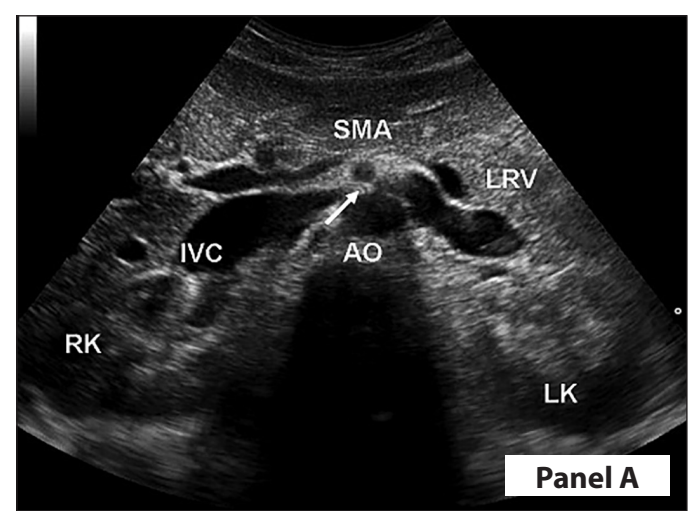

Transversal scan of the abdomen. RK=Right kidney; $\mathrm{LK}=$ Left kidney; IVC=Inferior vena cava; $\mathrm{AO}=$ aorta; $\mathrm{SMA}=$ superior mesenteric artery, $\mathrm{LRV}=$ left renal vein . The arrow indicates the point of LRV compression. tion and her vital signs were normal. Ultrasonography showed that both kidneys were of normal size and echostructure, with no hydronephrosis or bladder abnormalities. The left renal vein (LRV) was enlarged (15 $\mathrm{mm}$ ) with a winding course. Examination by Doppler ultrasound showed that blood flow was low with evidence of spontaneous echo contrast. The LRV was narrow $(2 \mathrm{~mm})$ between the aorta and the superior mesenteric artery (SMA) (Panel A). Color Doppler ultrasound showed a "mosaic" pattern of blood flow in the LRV, beyond the origin of the SMA. The peak velocity of systolic blood flow measured in the hilar tract and in the aortomesenteric portion of the LRV was $18.3 \mathrm{~cm} / \mathrm{sec}$ and $110.8 \mathrm{~cm} / \mathrm{sec}$ respectively (ratio 6.05), with a pressure gradient of $5 \mathrm{mmHg}$ (Panel B). Diagnosis: Renal Nut-

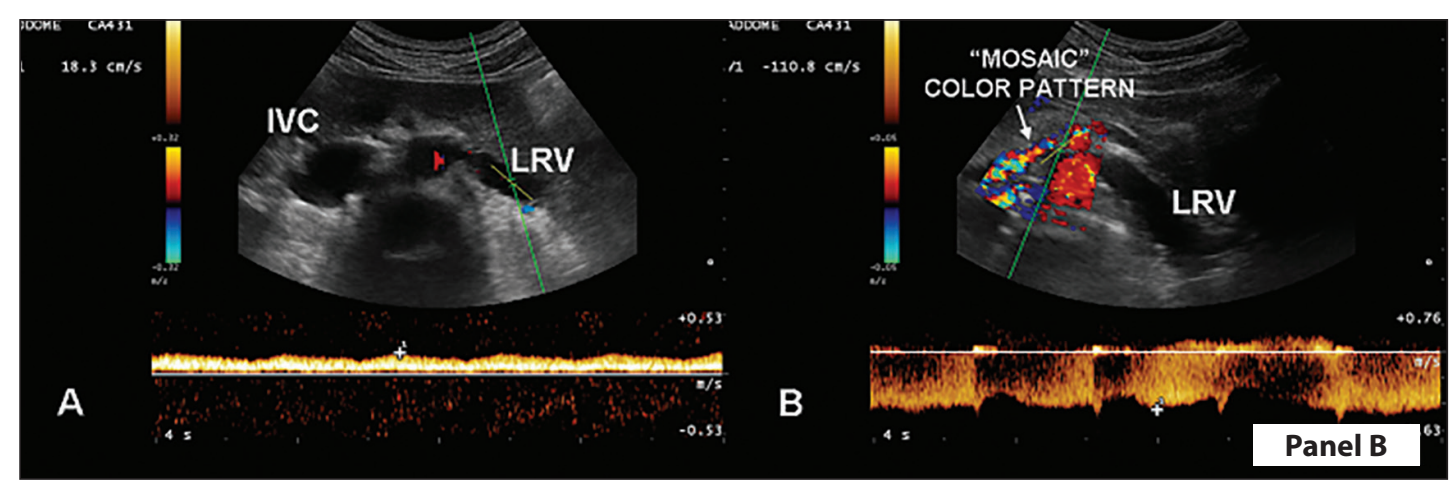

A: The peak velocity in the LRV is $18.3 \mathrm{~cm} / \mathrm{sec}$. B; The peak velocity in the LRV in aortomesenteric portion is 110.8 $\mathrm{cm} / \mathrm{sec}$. There is evidence of "mosaic" color pattern due to the turbulent flow. 
cracker Syndrome. Nutcracker syndrome is a vascular compression disorder, and refers to compression of the left renal vein between the superior mesenteric artery and the aorta. Its prevalence is unknown (1). Although often asymptomatic, this condition may occur with haematuria - more frequently micro-haematuria, flank or abdominal pain and varicocele, ovarian vein syndrome, LRV hypertension and pelviureteric varices may be part of this syndrome. The haematuria is probably related to the increased left renal vein pressure, which cause small venous ruptures into the collecting system. At present there is a lack of specific diagnostic tools. Measurement of the anteroposterior diameter of the LRV, together with Doppler ultrasound peak velocities may be useful in diagnosing nutcracker syndrome (2). According to many authors, a ratio higher than 5 between the Doppler ultrasound peak velocity of the narrow tract and the distended portion, is diagnostic, as well as the ratio between the diameter of the distended and the narrowed portions. In our case these values were 6.05 and 7.5 respectively (3).

Key words: Haematuria - Left renal vein - Superior mesenteric artery.
Authors' contributions: Conception and design: RC and EC; Acquisition, analysis and interpretation of data: RC and EC; Drafting the article: RC; Revising it critically for important intellectual content: RC and EC; Approved final version of the manuscript: RC and EC.

Conflict of interest: The authors declare that they have no conflict of interest.

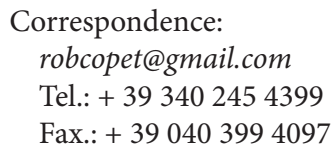

Received: 10 March 2017

Accepted: 22 May 2017

\section{References}

1. Hohenfellner M, Steinbach F, Schultz-Lampel D, Schantzen W, Walter K, Cramer BM, et al. The nutcracker syndrome: new aspects of pathophysiology, diagnosis and treatment. J Urol. 1991;146(3):685-8

2. Kim SH, Cho SW, Kim HD, Chung JW, Park JH, Han MC. Nutcracker syndrome: diagnosis with Doppler US. Radiology. 1996;198(1):93-7.

3. Kurklinsky AK, Rooke TW. Nutcracker Phenomenon and Nutcracker Syndrome. Mayo Clin Proc. 2010;85(6):552-9 